\title{
Moving toward a precise nutrition: preferential loading of seeds with essential nutrients over non-essential toxic elements
}

\section{Mather A. Khan, Norma Castro-Guerrero and David G. Mendoza-Cozatl*}

Division of Plant Sciences, Christopher S. Bond Life Sciences Center, University of Missouri, Columbia, MO, USA

\section{Edited by:}

Lorraine Elizabeth Williams, University of Southampton, UK

\section{Reviewed by:}

Agnieszka Sirko, Institute of

Biochemistry and Biophysics - Polish Academy of Sciences, Poland

Jian Feng Ma, Okayama University, Japan

\section{${ }^{*}$ Correspondence:}

David G. Mendoza-Cozatl, Division of Plant Sciences, Christopher S. Bond Life Sciences Center, University of Missouri, 1201 Rollins Street, Columbia, MO 65211, USA e-mail:mendozacozatld@ missouri.edu
Plants and seeds are the main source of essential nutrients for humans and livestock. Many advances have recently been made in understanding the molecular mechanisms by which plants take up and accumulate micronutrients such as iron, zinc, copper and manganese. Some of these mechanisms, however, also facilitate the accumulation of non-essential toxic elements such as cadmium (Cd) and arsenic (As). In humans, $\mathrm{Cd}$ and As intake has been associated with multiple disorders including kidney failure, diabetes, cancer and mental health issues. Recent studies have shown that some transporters can discriminate between essential metals and non-essential elements. Furthermore, sequestration of non-essential elements in roots has been described in several plant species as a key process limiting the translocation of non-essential elements to aboveground edible tissues, including seeds. Increasing the concentration of bioavailable micronutrients (biofortification) in grains while lowering the accumulation of non-essential elements will likely require the concerted action of several transporters. This review discusses the most recent advances on mineral nutrition that could be used to preferentially enrich seeds with micronutrients and also illustrates how precision breeding and transport engineering could be used to enhance the nutritional value of crops by re-routing essential and non-essential elements to separate sink tissues (roots and seeds).

Keywords: food security, heavy metals, long distance transport, seed loading, mineral nutrition

\section{INTRODUCTION}

Plants and seeds are the main dietary source of micronutrients (i.e., zinc, copper, manganese, and iron). Over the last 50 years, the production of cereals has tripled and the demand is expected to rise due to the constantly increasing population (Gregory and George, 2011). Any effort devoted to increase yield has to ensure that the nutritional value of seeds and grains is retained or, preferably, improved. The consumption of grains with low quantity of micronutrients has been associated with mineral deficiencies in humans (Burchi et al., 2011; Murgia et al., 2012). More than 2 billion people are affected by at least one type of micronutrient deficiency (White and Broadley, 2009; Waters and Sankaran, 2011). Another concern that could impact food security is the consumption of non-essential elements such as cadmium $(\mathrm{Cd})$ and arsenic (As) through contaminated food. More than $80 \%$ of $\mathrm{Cd}$ intake in humans comes from cereals and vegetables (Olsson et al., 2002; Egan et al., 2007). Natural occurrence of As in groundwater used for irrigation has been found around the world (Nordstrom, 2002; Rodriguez-Lado et al., 2013) potentially exposing more than 100 million people to As. Chronic exposure to low levels of $\mathrm{Cd}$ and As has been associated with cancer, diabetes, renal failure and neurological disorders (Satarug et al., 2010; Cho et al., 2013; Clemens et al., 2013).

Uptake and distribution of nutrients from the soil and within the plant is a dynamic process driven by root uptake transporters, root-to-shoot translocation (xylem transport) and source-to-sink transport through the phloem, which includes seed loading (Figure 1 and Table 1) (Mendoza-Cozatl et al., 2011; Waters and Sankaran, 2011; Sinclair and Kramer, 2012). Non-essential elements like As and $\mathrm{Cd}$ are taken up by plants and distributed between plant tissues by the same transporters that mobilize nutrients such as $\mathrm{Fe}^{2+}, \mathrm{Zn}^{2+}, \mathrm{Mn}^{2+}$, or $\mathrm{PO}_{4}{ }^{2-}$. Therefore, each of the steps required to move nutrients from the soil and into seeds (root uptake, translocation, xylem and phloem transport) represent an opportunity to increase the specificity towards essential nutrients and re-route non-essential elements to non-edible parts of the plant (Figure 1). Understanding the molecular mechanisms of each transport process and the contribution of different transporters to the overall allocation of essential and non-essential elements within plant tissues will help in developing crops that yield grains of higher nutritional value with lower content of non-essential elements. This review discusses the most recent discoveries in plant nutrition that could help achieving the goal of safe nutritional enrichment by means of precision breeding or transport engineering (Collard and Mackill, 2008; Nour-Eldin and Halkier, 2013).

\section{ROOT UPTAKE, VACUOLAR SEOUESTRATION, AND ROOT-TO-SHOOT TRANSLOCATION OF Cd AND As}

Root uptake represents the first step where selectivity towards essential elements can be improved and evidence suggest that it is possible to increase the selectivity of transporters towards 


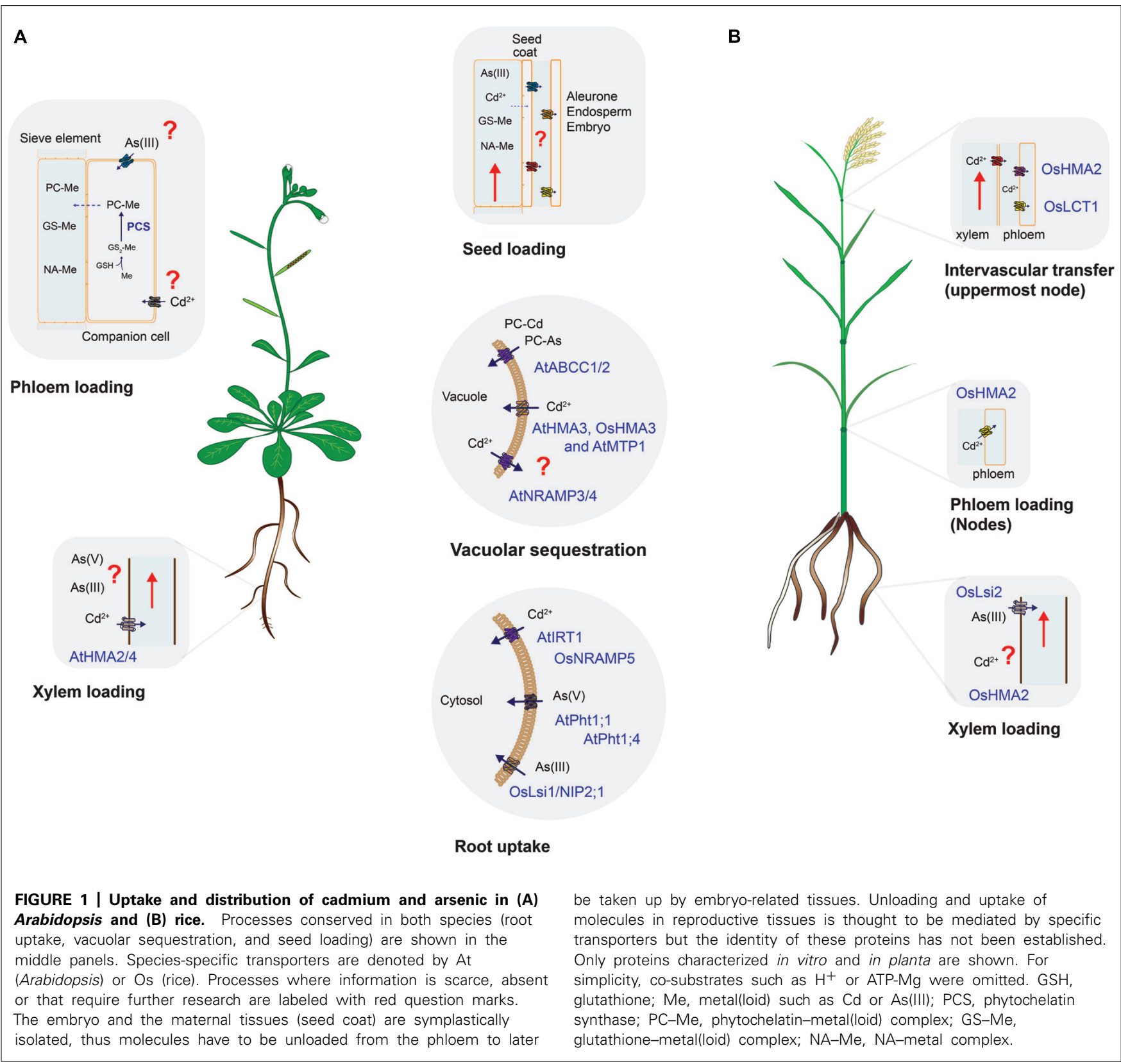

essential elements. In Arabidopsis, uptake of $\mathrm{Fe}^{2+}, \mathrm{Zn}^{2+}, \mathrm{Mn}^{2+}$, and $\mathrm{Cd}^{2+}$ is mediated by the ZIP family of transporters (Palmer and Guerinot, 2009; Mendoza-Cozatl et al., 2011). IRT1 is one of the best characterized members of this family and despite its broad specificity, previous studies have shown that changes in specific amino acid residues can modify its substrate specificity (Rogers et al., 2000). These studies have shown that discrimination between $\mathrm{Fe}^{2+} / \mathrm{Mn}^{2+}$ against $\mathrm{Cd}^{2+}$ is feasible. Selectivity of $\mathrm{Zn}^{2+}$ over $\mathrm{Cd}^{2+}$ is more challenging due to the highly similar electron configuration between these two elements. Selectivity of $\mathrm{Zn}^{2+}$ over $\mathrm{Cd}^{2+}$, however, has been demonstrated for mammalian ZnT transporters and bacterial P-type ATPases (Hoch et al., 2012). Conversely, selectivity of $\mathrm{Cd}^{2+}$ over $\mathrm{Zn}^{2+}$ has been found in the rice vacuolar P1B-type ATPase OsHMA3 and this gene has been identified as a major determinant limiting $\mathrm{Cd}$ accumulation in rice grains (see below; Ueno et al., 2010). The molecular basis and amino acid residues required for this metal selectivity have not been determined and could potentially be used in other crop species to limit the accumulation of $\mathrm{Cd}$ in seeds. In rice, the natural resistance-associated macrophage protein 5 (OsNRAMP5) has been identified as the main $\mathrm{Mn}^{2+}$ and $\mathrm{Cd}^{2+}$ transporter at the root level (Figure 1 and Table 1; Sasaki et al., 2012). OsIRT1 and OsIRT2 also mobilize $\mathrm{Fe}^{2+}, \mathrm{Zn}^{2+}$, and $\mathrm{Cd}^{2+}$ into roots but these transporters seem to play a minor role in Cd uptake compared to OsNRAMP5 (Sasaki et al., 2012). Substrate specificity studies could help identifying OsNRAMP5 natural variants with preference for $\mathrm{Mn}^{2+}$ over $\mathrm{Cd}^{2+}$ that can be introgressed into high-yield varieties of rice. 
In contrast to $\mathrm{Cd}$, As can occur in soils in several oxidation states, being arsenate $\left(\mathrm{As}^{\mathrm{V}}\right)$ and arsenite $\left(\mathrm{As}^{\mathrm{III}}\right)$ the most common ones (Ma et al., 2008; Ali et al., 2009; Zhao et al., 2009). In Arabidopsis, $\mathrm{As}^{\mathrm{V}}$ is taken up from aerobic soils by the phosphate transporters AtPht1;1 and 1;4 (Shin et al., 2004). The striking similarities between phosphate and arsenate in terms of $\mathrm{pKa}$ values, charged oxygen atoms and thermochemical radii differing only by $4 \%$ make a substrate specificity approach very challenging (Elias et al., 2012). Some bacterial phosphate binding proteins are able to discriminate between phosphate and arsenate and the structural basis for this discrimination has recently been established (Elias et al., 2012). Similar structural studies with plant transporters could help engineering phosphate transporters with high selectivity for phosphate over $\mathrm{As}^{\mathrm{V}}$. Once inside the cells, $\mathrm{As}^{\mathrm{V}}$ is quickly reduced to As ${ }^{\mathrm{III}}$, which is the predominant form of inorganic arsenic in plant cells (Ali et al., 2009; Zhao et al., 2009). Arsenite also occurs mostly in anaerobic soils and can be taken up by plants thus affecting flooded crops like rice. OsNIP2;1, a member of the Nod26-like major intrinsic protein (NIP) has been identified as a major pathway for As ${ }^{\mathrm{III}}$ uptake into rice roots (Ma etal., 2008; Zhao et al., 2009). The physiological function of OsNIP2;1, also known as Lsi1, is silicon uptake. Lsi2 on the other hand, functions as a silicon and $\mathrm{As}{ }^{\mathrm{III}}$ exporter and both Lsi1 and Lsi2 are the main transporters controlling As ${ }^{\mathrm{III}}$ uptake and translocation to shoots (Figure 1 and Table 1). Recently, there have been some efforts to identify amino acid residues affecting the substrate selectivity of OsNIP2;1/Lsi1 but so far no selectivity of essential nutrients over $\mathrm{As}^{\mathrm{III}}$ has been found (Mitani-Ueno et al., 2011).
Sequestration in root vacuoles has been demonstrated as the major process limiting the translocation of As and $\mathrm{Cd}$ to shoots and seeds (Ueno et al., 2010; Kopittke et al., 2013). Similar to $\mathrm{Cd}^{2+}, \mathrm{As}^{\mathrm{III}}$ has a strong affinity for thiol-containing molecules such as cysteine, glutathione and phytochelatins (PCs). PCs are glutathione-derived peptides synthesized in response to $\mathrm{As}^{\mathrm{III}}$ or $\mathrm{Cd}^{2+}$ exposure (Mendoza-Cozatl et al., 2005). PC-metal(loid) complexes are transported into vacuoles by ATP-binding cassette transporters and, in Arabidopsis, $\mathrm{ABCC} 1$ and $\mathrm{ABCC} 2$ have been identified as the main transporters mediating PC uptake into vacuoles (Song et al., 2010b). Orthologs of AtABCC1 have been identified in grasses including rice, maize and barley and kinetic analysis using vacuoles isolated from barley suggest that the transport mechanism is conserved across species (Song et al., 2013). Furthermore, a recent analysis using six rice varieties showing low and high accumulation of arsenic in grains suggest that PCs play a key role trapping inorganic As in roots, limiting the transfer of As to shoots and grains (Batista et al., 2013). PCs are usually considered as a mechanism to detoxify non-essential elements; however, there is evidence to suggest that PCs also play a role in the homeostasis of essential metals such as $\mathrm{Zn}$ and Mn (Tennstedt et al., 2009; Song etal., 2013). Therefore, more studies are needed to explore whether increasing vacuolar sequestration of PCs in roots could have a negative impact on the content of essential elements in aboveground edible tissues.

P1B-type ATPases have also been shown to play a key role sequestering Cd in root vacuoles (Ueno et al., 2010). OsHMA3, a vacuolar P1B-type ATPase was found to be responsible for $85.6 \%$ of the variance in $\mathrm{Cd}$ content between low- and high-cadmium

Table 1 | Transporters mediating the uptake and mobilization of arsenic or cadmium (discussed in this review).

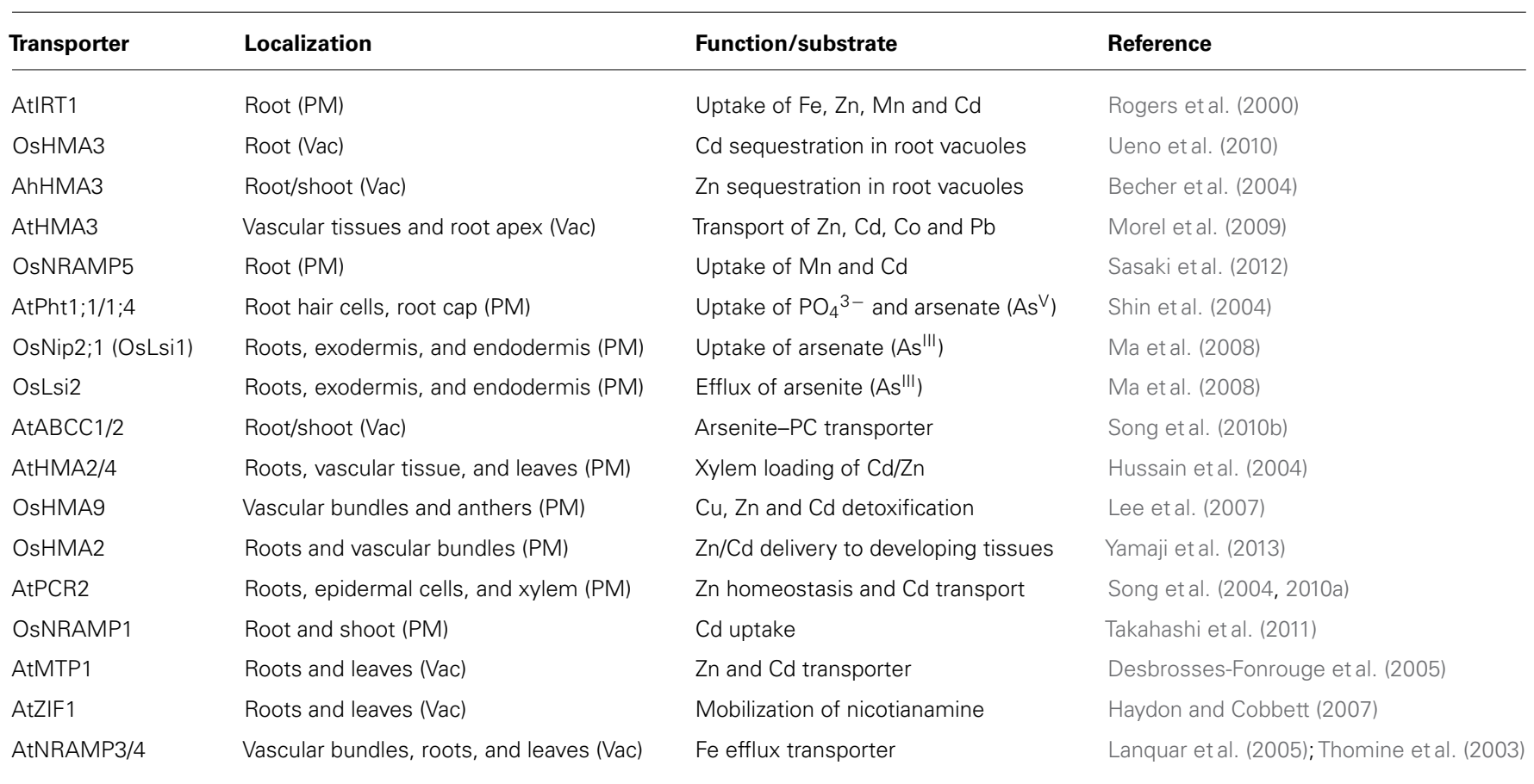

The first two letters denote the organism of origin: At, Arabidopsis thaliana; Ah, Arabidopsis halleri; Os, Oryza sativa. Subcellular localization is shown in parenthesis: PM, plasma membrane; Vac, vacuole (tonoplast). See also Figure 1 and text for further details. 
accumulation varieties of rice (Ueno etal., 2010). OsHMA3 sequesters $\mathrm{Cd}$ in root vacuoles, thus preventing it from reaching shoots and grains. Of particular interest is the fact that OsHMA3 seems to be highly specific for $\mathrm{Cd}$ while the Arabidopsis halleri HMA3 has preference for $\mathrm{Zn}$ and the A. thaliana HMA3 shows broad substrate specificity being able to transport $\mathrm{Co}, \mathrm{Pb}, \mathrm{Cd}$, and Zn (Becher et al., 2004; Morel et al., 2009). Structural studies using OsHMA3, AhHMA3, and AtHMA3 could help identifying which residues give the high specificity of OsHMA3 for Cd over essential elements such as $\mathrm{Zn}$ or Mn.

Xylem loading is the next step where translocation of nonessential elements can be blocked allowing only essential elements to reach leaves and seeds. In Arabidopsis $\mathrm{Cd}$ and $\mathrm{Zn}$ are loaded into the xylem by two P1B-type ATPases, HMA2, and HMA4 (Hussain et al., 2004). It would be interesting to determine whether it is possible to alter the selectivity of HMA2 and 4 to favor the translocation of $\mathrm{Zn}$ over Cd. PCR2 is another Arabidopsis protein that has been implicated in the long-distance transport of Cd and Zn (Song et al., 2004, 2010a). However, PCR2 expression is not restricted to xylem parenchyma suggesting that PCR2 may have other roles beside root-to-shoot translocation of $\mathrm{Cd}$ and Zn (Song etal., 2004, 2010a). Less information is known about the HMA family in rice, OsHMA2 has been proposed to mediate the loading of $\mathrm{Cd}$ and $\mathrm{Zn}$ into the xylem (Takahashi et al., 2012), together with OsHMA9 and proteins from the NRAMP family of transporters (OsNRAMP1; Lee et al., 2007; Takahashi et al., 2011). OsHMA5 has also been localized in root pericycle cells and xylem but OsHMA5 seems to be a copper-specific transporter with little or no effect on the accumulation of $\mathrm{Fe}, \mathrm{Mn}$, or $\mathrm{Zn}$ in rice tissues (Deng et al., 2013).

Metal(loid)-ligand chemistry is another process that is key to understand how elements are mobilized throughout the plant. For instance, $\mathrm{Fe}$ and $\mathrm{Cd}$ are taken up by IRT1, but once inside the cell, $\mathrm{Fe}$ and $\mathrm{Cd}$ will form complexes with different ligands; iron will prefer oxygen-containing molecules such as citrate and nicotianamine while $\mathrm{Cd}$ will bind to thiol- and nitrogen-containing compounds such as glutathione, PCs and histidine (Meda et al., 2007; Mendoza-Cozatl et al., 2008; RellánÁlvarez et al., 2008). This metal-ligand interaction explains why $\mathrm{Cd}$ and $\mathrm{Zn}$, but not $\mathrm{Fe}$, compete for the same ligands and transporters.

Inorganic arsenic can reach the xylem as $\mathrm{As}^{\mathrm{V}}$ or $\mathrm{As}^{\mathrm{III}}$ but fluorescence-X-ray absorption near-edge spectroscopy (fluorescence-XANES) has recently shown that As ${ }^{\mathrm{III}}$ is the predominant form of arsenic in plant cells (Kopittke et al., 2013). Similar to Cd, As ${ }^{\mathrm{III}}$ has a strong affinity for thiol groups and, consequently, most of the As ${ }^{\mathrm{III}}$ found in the cortex and stele was identified as As(III)-thiol complexes (Kopittke et al., 2013). In rice, Lsi2 has been identified as the transporter mediating As ${ }^{\mathrm{III}}$ loading into the xylem (Ma et al., 2008). In Arabidopsis, it is not clear which transporter mediates this process but transporters of the NIP family are possible candidates that are currently being evaluated (Ali et al., 2009; Kamiya et al., 2009).

\section{INTRACELLULAR TRANSPORT AND PHLOEM LOADING}

In contrast to natural As and Cd hyperaccumulators, Arabidopsis, rice and wheat accumulate only a minor fraction of As and Cd in leaves. In Arabidopsis, MTP1 has been described as a Cd/Zn vacuolar transporter and structure-function analyses suggest that it is possible to increase the selectivity of AtMTP1 towards $\mathrm{Zn}$ (Desbrosses-Fonrouge et al., 2005; Kawachi et al., 2012; Podar et al., 2012). OsMTP8.1 has been described as a vacuolar Mnspecific transporter in rice but its role on Cd uptake has not been evaluated (Chen et al., 2013). ZIF1 is a tonoplast-localized transporter that mobilizes nicotianamine into Arabidopsis vacuoles thus affecting Fe and Zn homeostasis (Haydon et al., 2012). Deletion of ZIF1 leads to Cd hypersensitivity in Arabidopsis but it is not clear whether this sensitivity is the result of an impaired Fe/Zn homeostasis or whether ZIF1-mediated transport of nicotianamine plays a role in sequestering $\mathrm{Cd}$ in shoot vacuoles. Arabidopsis NRAMP3 and 4 are transporters that export Fe from vacuoles (Lanquar et al., 2005). When expressed in yeast, NRAMP3 and 4 can mobilize $\mathrm{Cd}$ and it has recently been shown that photosynthesis in the Arabidopsis nramp3 nramp4 double mutant is particularly sensitive to Cd (Molins et al., 2013). NRAMP proteins, like ZIP transporters, have broad substrate specificity and more structural analyses are needed to determine how NRAMP proteins could be used to restrict the accumulation of nonessential elements while preserving the homeostasis of essential metals.

The low accumulation of As and Cd in shoots observed in nonhyperaccumulator species was thought to be solely the result of limited translocation to shoots but recent evidence suggest that low-retention in leaves together with phloem-mediated transport to roots could play an important role re-allocating non-essential elements from shoots to roots (Mendoza-Cozatl et al., 2008, 2011; Ye et al., 2010). Nutrients and non-essential molecules are loaded into seeds through the phloem, which is a vascular system made up of two highly specialized cells, companion cells and sieve elements (Moore et al., 2013; Slewinski et al., 2013). Companion cells transfer molecules into sieve elements for long-distance transport, thus transporters expressed in companion cells are critical proteins that could impact phloem sap and seed composition. In contrast to xylem transport, phloem loading of micronutrients and non-essential elements remains largely unexplored. However, the phloem plays a key role in delivering nutrients to developing seeds, where xylem transport is limited. Arabidopsis YSL1 and YSL3 are nicotianamine-metal transporters required to mobilize $\mathrm{Mn}, \mathrm{Zn}$, $\mathrm{Cu}$ and $\mathrm{Fe}$ out of senescing leaves but their role in $\mathrm{Cd}$ mobilization, if any, has not been evaluated. Similarly, rice OsYSL16 has been characterized as a $\mathrm{Cu}-\mathrm{NA}$ transporter while OsYSL6 is required to detoxify excess of Mn but neither OsYSL16 or OsYSL6 seem to participate in Cd mobilization to developing grains (Sasaki et al., 2011; Chen et al., 2013).

Phloem loading mechanisms may vary across species and in the case of rice, xylem-to-phloem transfer, particularly at the node connected to the flag leaf and panicle, appears to be the major route for Cd loading into the phloem. Recently, OsLCT1 was identified as a strong candidate mediating the intervascular transfer of $\mathrm{Cd}$ into the phloem. OsLCT1 is strongly expressed in nodes during grain ripening and RNAi-mediated knockdown of OsLCT1 resulted in $50 \%$ less $\mathrm{Cd}$ in grains without affecting the concentration of essential micronutrients or grain yield (Uraguchi etal., 2011). OsHMA2, besides being expressed in roots, is also expressed in 
the nodes (phloem) at reproductive stage and insertional mutants showed less $\mathrm{Cd}$ and $\mathrm{Mn}$ in the upper nodes compared to wild-type (Yamaji et al., 2013). Thus, OsLCT1 and OsHMA2 could be the target for further manipulation to limit the translocation of $\mathrm{Cd}$ into rice grains.

\section{TOWARD A PRECISE NUTRITION}

Several reviews have recently discussed how QTL mapping, GWAS, transgenic approaches and conventional breeding have successfully been used to increase the concentration of micronutrients in seeds (White and Broadley, 2005, 2009; Sperotto et al., 2012). From these studies it is clear that several processes regulating the movement of elements into seeds are still largely unknown and that the mechanisms mediating long-distance transport of nutrients vary widely across species. Moreover, because non-essential elements such as As and Cd use the transport systems for essential nutrients to move within the plant, efforts to increase the content of micronutrients in crops could also increase the concentration of toxic elements in seeds. This is a serious threat to food security particularly in places where the occurrence of non-essential toxic elements in groundwater used for irrigation is above safety limits.

A successful precision breeding or transport engineering approach to produce crops able to accumulate micronutrients over non-essential metals should consider: (i) high substrate selectivity of transporters for essential metals, (ii) tissue-specific expression and subcellular localization, (iii) the developmental stage at which the transporter is needed, and (iv) the need of ligand molecules in sink tissues to keep micronutrients bioavailable and prevent toxicity. Research suggests that successful approaches will likely require the simultaneous modification of more than one step in different tissues. Cross-species studies of transporters of the same family, crystallography and site-directed mutagenesis have shown to be extremely useful to identify amino acid residues critical to enhance the selectivity of transporters (Becher et al., 2004; Courbot et al., 2007; Zimmermann et al., 2009). The lower cost of next-generation sequencing together with natural variant accessions available for some crops makes feasible the identification of transporters that can later be introgressed into high yield varieties to obtain safer and more nutritious grains. While transgenic approaches have a faster turnaround compared to traditional breeding, other technologies such as precision breeding or genome editing are non-transgenic alternatives that could achieve similar results in comparable time frames. Also, the development of tissue-specific translatome analysis in Arabidopsis offers the opportunity, for the first time, to study the regulation of transporters at tissue-specific level (Mustroph et al., 2009). Phloem unloading and re-uptake of nutrients by seed tissues is the last barrier where the accumulation of non-essential metals in seeds could be blocked. The identity and regulation of transporters mediating phloem unloading and seed loading are largely unknown and phloem-specific translatome analysis in seed loading tissues could help identifying such transporters. Translatome analyses are also currently being established in crop plants (Mendoza-Cozatl and Stacey, unpublished) and will likely provide more details about the mechanisms mediating the mobilization of nutrients and toxic elements within the plant and ultimately into seeds.
The urgent need of providing more nutritious food to a rapidly growing population is challenging considering environmental issues such as climate change, contamination of soil and water, and land available, but sustainable solutions to these global challenges are more likely to come from cross-disciplinary approaches between farmers, breeders, biologists, geneticists and bioengineers.

\section{ACKNOWLEDGMENTS}

This work was supported by the US National Science Foundation (IOS-1252706) and the University of Missouri Research Board Grant (Project CB000519).

\section{REFERENCES}

Ali, W., Isayenkov, S. V., Zhao, F. J., and Maathuis, F. J. (2009). Arsenite transport in plants. Cell. Mol. Life Sci. 66, 2329-2339. doi: 10.1007/s00018-009-0021-7

Batista, B. L., Nigar, M., Mestrot, A., Alves Rochad, B., Barbosa, F., Price, A. H., et al. (2013). Identification and quantification of phytochelatins in roots of rice at long-term exposure: evidence of individual role on arsenic accumulation. J. Exp. Bot. [in press].

Becher, M., Talke, I. N., Krall, L., and Kramer, U. (2004). Crossspecies microarray transcript profiling reveals high constitutive expression of metal homeostasis genes in shoots of the zinc hyperaccumulator Arabidopsis halleri. Plant J. 37, 251-268. doi: 10.1046/j.1365-313X.2003. 01959.x

Burchi, F., Fanzo, J., and Frison, E. (2011). The role of food and nutrition system approaches in tackling hidden hunger. Int. J. Environ. Res. Public Health 8, 358373. doi: 10.3390/ijerph8020358

Chen, Z., Fujii, Y., Yamaji, N., Masuda, S., Takemoto, Y., Kamiya, T., et al. (2013). Mn tolerance in rice is mediated by MTP8.1, a member of the cation diffusion facilitator family. J. Exp. Bot. 64, 4375-4387. doi: 10.1093/jxb/ert243

Cho, Y. A., Kim, J., Woo, H. D., and Kang, M. (2013). Dietary cadmium intake and the risk of cancer: a meta-analysis. PLOS ONE 8:e75087. doi: 10.1371/journal.pone.0075087

Clemens, S., Aarts, M. G., Thomine, S., and Verbruggen, N. (2013). Plant science: the key to preventing slow cadmium poisoning. Trends Plant Sci. 18, 92-99. doi: 10.1016/j.tplants.2012.08.003

Collard, B. C., and Mackill, D. J. (2008). Marker-assisted selection: an approach for precision plant breeding in the twenty-first century. Philos. Trans. R. Soc. Lond. B Biol. Sci. 363, 557-572. doi: 10.1098/rstb.2007.2170

Courbot, M., Willems, G., Motte, P., Arvidsson, S., Roosens, N., Saumitou-Laprade, P., et al. (2007). A major quantitative trait locus for cadmium tolerance in Arabidopsis halleri colocalizes with HMA4, a gene encoding a heavy metal ATPase. Plant Physiol. 144, 1052-1065. doi: 10.1104/pp.106.09513

Deng, F., Yamaji, N., Xia, J., and Ma, J. F. (2013). A member of the heavy metal P-type ATPase OsHMA5 is involved in xylem loading of copper in rice. Plant Physiol. 163, 1353-1362. doi: 10.1104/pp.113.226225

Desbrosses-Fonrouge, A. G., Voigt, K., Schröder, A., Arrivault, S., Thomine, S., and Krämer, U. (2005). Arabidopsis thaliana MTP1 is a Zn transporter in the vacuolar membrane which mediates $\mathrm{Zn}$ detoxification and drives leaf $\mathrm{Zn}$ accumulation. FEBS Lett. 579, 4165-4174 doi: 10.1016/j.febslet.2005.06.046

Egan, S. K., Bolger, P. M., and Carrington, C. D. (2007). Update of US FDA's Total Diet Study food list and diets. J. Expo. Sci. Environ. Epidemiol. 17, 573-582. doi: 10.1038/sj.jes. 7500554

Elias, M., Wellner, A., Goldin-Azulay, K., Chabriere, E., Vorholt, J. A., Erb, T. J., et al. (2012). The molecular basis of phosphate discrimination in arsenate-rich environments. Nature 491, 134-137. doi: 10.1038/nature11517

Gregory, P. J., and George, T. S. (2011). Feeding nine billion: the challenge to sustainable crop production. J. Exp. Bot. 62, 5233-5239. doi: 10.1093/jxb/err232

Haydon, M. J., and Cobbett, C. S. (2007). A novel major facilitator superfamily protein at the tonoplast influences zinc tolerance and accumulation in Arabidopsis. Plant Physiol. 143, 1705-1719. doi: 10.1104/pp.106.092015

Haydon, M. J., Kawachi, M., Wirtz, M., Hillmer, S., Hell, R., and Kramer, U. (2012). Vacuolar nicotianamine has critical and distinct roles under iron deficiency and for zinc sequestration in Arabidopsis. Plant Cell 24, 724-737. doi: $10.1105 /$ tpc.111.095042 
Hoch, E., Lin, W., Chai, J., Hershfinkel, M., Fu, D., and Sekler, I. (2012). Histidine pairing at the metal transport site of mammalian $\mathrm{ZnT}$ transporters controls $\mathrm{Zn}^{2+}$ over $\mathrm{Cd}^{2+}$ selectivity. Proc. Natl. Acad. Sci. U.S.A. 109, 7202-7207. doi: 10.1073/pnas. 1200362109

Hussain, D., Haydon, M. J., Wang, Y., Wong, E., Sherson, S. M., Young, J., et al. (2004). P-type ATPase heavy metal transporters with roles in essential zinc homeostasis in Arabidopsis. Plant Cell 16, 1327-1339. doi: 10.1105/tpc. 020487

Kamiya, T., Tanaka, M., Mitani, N., Ma, J. F., Maeshima, M., and Fujiwara, T. (2009). NIP1;1, an aquaporin homolog, determines the arsenite sensitivity of Arabidopsis thaliana. J. Biol. Chem. 284, 2114-2120. doi: 10.1074/jbc.M806881200

Kawachi, M., Kobae, Y., Kogawa, S., Mimura, T., Kramer, U., and Maeshima, M. (2012). Amino acid screening based on structural modeling identifies critical residues for the function, ion selectivity and structure of Arabidopsis MTP1. FEBS J. 279, 2339-2356. doi: 10.1111/j.1742-4658.2012.08613.x

Kopittke, P. M., De Jonge, M. D., Wang, P., Mckenna, B. A., Lombi, E., Paterson, D. J., et al. (2013). Laterally resolved speciation of arsenic in roots of wheat and rice using fluorescence-XANES imaging. New Phytol. 201, 1251-1262. doi: $10.1111 /$ nph. 12595

Lanquar, V., Lelievre, F., Bolte, S., Hames, C., Alcon, C., Neumann, D., et al. (2005). Mobilization of vacuolar iron by AtNRAMP3 and AtNRAMP4 is essential for seed germination on low iron. EMBO J. 24, 4041-4051. doi: 10.1038/sj.emboj.7600864

Lee, S., Kim, Y. Y., Lee, Y., and An, G. (2007). Rice P1B-type heavy-metal ATPase, OsHMA9, is a metal efflux protein. Plant Physiol. 145, 831-842. doi: $10.1104 / p p \cdot 107.102236$

Ma, J. F., Yamaji, N., Mitani, N., Xu, X. Y., Su, Y. H., Mcgrath, S. P., et al. (2008) Transporters of arsenite in rice and their role in arsenic accumulation in rice grain Proc. Natl. Acad. Sci. U.S.A. 105, 9931-9935. doi: 10.1073/pnas.0802361105

Meda, A. R., Scheuermann, E. B., Prechsl, U. E., Erenoglu, B., Schaaf, G., Hayen, H., et al. (2007). Iron acquisition by phytosiderophores contributes to cadmium tolerance. Plant Physiol. 143, 1761-1773. doi: 10.1104/pp.106. 094474

Mendoza-Cozatl, D. G., Butko, E., Springer, F., Torpey, J. W., Komives, E. A., Kehr, J., et al. (2008). Identification of high levels of phytochelatins, glutathione and cadmium in the phloem sap of Brassica napus. A role for thiol-peptides in the longdistance transport of cadmium and the effect of cadmium on iron translocation. Plant J. 54, 249-259. doi: 10.1111/j.1365-313X.2008.03410.x

Mendoza-Cozatl, D. G., Loza-Tavera, H., Hernandez-Navarro, A., and MorenoSanchez, R. (2005). Sulfur assimilation and glutathione metabolism under cadmium stress in yeast, protists and plants. FEMS Microbiol. Rev. 29, 653-671. doi: 10.1016/j.femsre.2004.09.004

Mendoza-Cozatl, D. G., Jobe, T. O., Hauser, F., and Schroeder, J. I. (2011). Long-distance transport, vacuolar sequestration, tolerance, and transcriptiona responses induced by cadmium and arsenic. Curr. Opin. Plant Biol. 14, 554-562. doi: 10.1016/j.pbi.2011.07.004

Mitani-Ueno, N., Yamaji, N., Zhao, F. J., and Ma, J. F. (2011). The aromatic/arginine selectivity filter of NIP aquaporins plays a critical role in substrate selectivity for silicon, boron, and arsenic. J. Exp. Bot. 62, 4391-4398. doi: 10.1093/jxb/err158

Molins, H., Michelet, L., Lanquar, V., Agorio, A., Giraudat, J., Roach, T., et al. (2013). Mutants impaired in vacuolar metal mobilization identify chloroplasts as a target for cadmium hypersensitivity in Arabidopsis thaliana. Plant Cell Environ. 36, 804-817. doi: 10.1111/pce.12016

Moore, K. L., Chen, Y., Van De Meene, A. M., Hughes, L., Liu, W., Geraki, T., et al. (2013). Combined NanoSIMS and synchrotron X-ray fluorescence reveal distinct cellular and subcellular distribution patterns of trace elements in rice tissues. New Phytol. 201, 104-115. doi: 10.1111/nph.12497.

Morel, M., Crouzet, J., Gravot, A., Auroy, P., Leonhardt, N., Vavasseur, A., et al. (2009). AtHMA3, a P1B-ATPase allowing $\mathrm{Cd} / \mathrm{Zn} / \mathrm{Co} / \mathrm{Pb}$ vacuolar storage in Arabidopsis. Plant Physiol. 149, 894-904. doi: 10.1104/pp.108.130294

Murgia, I., Arosio, P., Tarantino, D., and Soave, C. (2012). Biofortification for combating "hidden hunger" for iron. Trends Plant Sci. 17, 47-55. doi: 10.1016/j.tplants.2011.10.003

Mustroph, A., Zanetti, M. E., Jang, C. J., Holtan, H. E., Repetti, P. P., Galbraith, D. W., et al. (2009). Profiling translatomes of discrete cell populations resolves altered cellular priorities during hypoxia in Arabidopsis. Proc. Natl. Acad. Sci. U.S.A. 106, 18843-18848. doi: 10.1073/pnas.0906131106

Nordstrom, D. K. (2002). Public health. Worldwide occurrences of arsenic in ground water. Science 296, 2143-2145. doi: 10.1126/science.1072375
Nour-Eldin, H. H., and Halkier, B. A. (2013). The emerging field of transport engineering of plant specialized metabolites. Curr. Opin. Biotechnol. 24, 263-270. doi: 10.1016/j.copbio.2012.09.006

Olsson, I. M., Bensryd, I., Lundh, T., Ottosson, H., Skerfving, S., and Oskarsson, A. (2002). Cadmium in blood and urine-impact of sex, age, dietary intake, iron status, and former smoking-association of renal effects. Environ. Health Perspect. 110, 1185-1190. doi: 10.1289/ehp.021101185

Palmer, C. M., and Guerinot, M. L. (2009). Facing the challenges of Cu, Fe and Zn homeostasis in plants. Nat. Chem. Biol. 5, 333-340. doi: 10.1038/nchembio. 166

Podar, D., Scherer, J., Noordally, Z., Herzyk, P., Nies, D., and Sanders, D. (2012). Metal selectivity determinants in a family of transition metal transporters. J. Biol. Chem. 287, 3185-3196. doi: 10.1074/jbc.M111.305649

Rellán-Álvarez, R., Abadía, J., and Álvarez-Fernández, A. (2008). Formation of metal-nicotianamine complexes as affected by $\mathrm{pH}$, ligand exchange with citrate and metal exchange. A study by electrospray ionization time-of-flight mass spectrometry. Rapid Commun. Mass Spectrom.22, 1553-1562. doi: 10.1002/rcm.3523

Rodriguez-Lado, L., Sun, G., Berg, M., Zhang, Q., Xue, H., Zheng, Q., et al. (2013). Groundwater arsenic contamination throughout China. Science 341, 866-868. doi: $10.1126 /$ science. 1237484

Rogers, E. E., Eide, D. J., and Guerinot, M. L. (2000). Altered selectivity in an Arabidopsis metal transporter. Proc. Natl. Acad. Sci. U.S.A. 97, 12356-12360. doi: 10.1073/pnas.210214197

Sasaki, A., Yamaji, N., Xia, J., and Ma, J. F. (2011). OsYSL6 is involved in the detoxification of excess manganese in rice. Plant Physiol. 157, 1832-1840. doi: 10.1104/pp.111.186031

Sasaki, A., Yamaji, N., Yokosho, K., and Ma, J. F. (2012). Nramp5 is a major transporter responsible for manganese and cadmium uptake in rice. Plant Cell 24, 2155-2167. doi: 10.1105/tpc.112.096925

Satarug, S., Garrett, S. H., Sens, M. A., and Sens, D. A. (2010). Cadmium, environmental exposure, and health outcomes. Environ. Health Perspect. 118, 182-190. doi: 10.1289/ehp.0901234

Shin, H., Shin, H. S., Dewbre, G. R., and Harrison, M. J. (2004). Phosphate transport in Arabidopsis: Pht1;1 and Pht1;4 play a major role in phosphate acquisition from both low- and high-phosphate environments. Plant J. 39, 629-642. doi: 10.1111/j.1365-313X.2004.02161.x

Sinclair, S. A., and Kramer, U. (2012). The zinc homeostasis network of land plants. Biochim. Biophys. Acta 1823, 1553-1567. doi: 10.1016/j.bbamcr.2012.05.016

Slewinski, T. L., Zhang, C., and Turgeon, R. (2013). Structural and functional heterogeneity in phloem loading and transport. Front. Plant Sci. 4:244. doi: 10.3389/fpls.2013.00244

Song, W. Y., Choi, K. S., Kim Do, Y., Geisler, M., Park, J., Vincenzetti, V., et al. (2010a). Arabidopsis PCR2 is a zinc exporter involved in both zinc extrusion and longdistance zinc transport. Plant Cell 22, 2237-2252. doi: 10.1105/tpc. 109.070185

Song, W. Y., Park, J., Mendoza-Cozatl, D. G., Suter-Grotemeyer, M., Shim, D., Hortensteiner, S., et al. (2010b). Arsenic tolerance in Arabidopsis is mediated by two ABCC-type phytochelatin transporters. Proc. Natl. Acad. Sci. U.S.A. 107, 21187-21192. doi: 10.1073/pnas.1013964107

Song, W. Y., Martinoia, E., Lee, J., Kim, D., Kim, D. Y., Vogt, E., et al. (2004). A novel family of cys-rich membrane proteins mediates cadmium resistance in Arabidopsis. Plant Physiol. 135, 1027-1039. doi: 10.1104/pp.103.037739

Song, W. Y., Mendoza-Cozatl, D., Lee, Y., Schroeder, J., Ahn, S. N., Lee, H. S., et al. (2013). Phytochelatin-metal(loid) transport into vacuoles shows different substrate preferences in barley and Arabidopsis. Plant Cell Environ. doi: 10.1111/pce.12227 [Epub ahead of print].

Sperotto, R. A., Ricachenevsky, F. K., Waldow Vde, A., and Fett, J. P. (2012). Iron biofortification in rice: it's a long way to the top. Plant Sci. 190, 24-39. doi: 10.1016/j.plantsci.2012.03.004

Takahashi, R., Ishimaru, Y., Senoura, T., Shimo, H., Ishikawa, S., Arao, T., et al. (2011). The OsNRAMP1 iron transporter is involved in $\mathrm{Cd}$ accumulation in rice. J. Exp. Bot. 62, 4843-4850. doi: 10.1093/jxb/err136

Takahashi, R., Ishimaru, Y., Shimo, H., Ogo, Y., Senoura, T., Nishizawa, N. K., et al. (2012). The OsHMA2 transporter is involved in root-to-shoot translocation of $\mathrm{Zn}$ and Cd in rice. Plant Cell Environ. 35, 1948-1957. doi: 10.1111/j.13653040.2012.02527.x

Tennstedt, P., Peisker, D., Bottcher, C., Trampczynska, A., and Clemens, S. (2009). Phytochelatin synthesis is essential for the detoxification of excess zinc and contributes significantly to the accumulation of zinc. Plant Physiol. 149, 938-948. doi: 10.1104/pp.108.127472 
Thomine, S., Lelièvre, F., Debarbieux, E., Schroeder, J. I., and Barbier-Brygoo, H. (2003). AtNRAMP3, a multispecific vacuolar metal transporter involved in plant responses to iron deficiency. Plant J. 34, 685-695. doi: 10.1046/j.1365313X.2003.01760.x

Ueno, D., Yamaji, N., Kono, I., Huang, C. F., Ando, T., Yano, M., et al. (2010). Gene limiting cadmium accumulation in rice. Proc. Natl. Acad. Sci. U.S.A. 107, 16500-16505. doi: 10.1073/pnas.1005396107

Uraguchi, S., Kamiya, T., Sakamoto, T., Kasai, K., Sato, Y., Nagamura, Y., et al (2011). Low-affinity cation transporter (OsLCT1) regulates cadmium transport into rice grains. Proc. Natl. Acad. Sci. U.S.A. 108, 20959-20964. doi: 10.1073/pnas.1116531109

Waters, B. M., and Sankaran, R. P. (2011). Moving micronutrients from the soil to the seeds: genes and physiological processes from a biofortification perspective. Plant Sci. 180, 562-574. doi: 10.1016/j.plantsci.2010.12.003

White, P. J., and Broadley, M. R. (2005). Biofortifying crops with essential mineral elements. Trends Plant Sci. 10, 586-593. doi: 10.1016/j.tplants.2005.10.001

White, P. J., and Broadley, M. R. (2009). Biofortification of crops with seven mineral elements often lacking in human diets-iron, zinc, copper, calcium, magnesium, selenium and iodine. New Phytol. 182, 49-84. doi: 10.1111/j.14698137.2008.02738.x

Yamaji, N., Xia, J., Mitani-Ueno, N., Yokosho, K., and Feng Ma, J. (2013). Preferential delivery of zinc to developing tissues in rice is mediated by P-type heavy metal ATPase OsHMA2. Plant Physiol. 162, 927-939. doi: 10.1104/pp.113.216564

Ye, W. L., Wood, B. A., Stroud, J. L., Andralojc, P. J., Raab, A., Mcgrath, S. P., et al. (2010). Arsenic speciation in phloem and xylem exudates of castor bean. Plant Physiol. 154, 1505-1513. doi: 10.1104/pp.110.163261
Zhao, F. J., Ma, J. F., Meharg, A. A., and Mcgrath, S. P. (2009). Arsenic uptake and metabolism in plants. New Phytol. 181, 777-794. doi: 10.1111/j.14698137.2008.02716.x

Zimmermann, M., Clarke, O., Gulbis, J. M., Keizer, D. W., Jarvis, R. S., Cobbett, C. S., et al. (2009). Metal binding affinities of Arabidopsis zinc and copper transporters: selectivities match the relative, but not the absolute, affinities of their amino-terminal domains. Biochemistry 48, 11640-11654. doi: 10.1021/ bi901573b

Conflict of Interest Statement: The authors declare that the research was conducted in the absence of any commercial or financial relationships that could be construed as a potential conflict of interest.

Received: 01 December 2013; accepted: 03 February 2014; published online: 20 February 2014.

Citation: Khan MA, Castro-Guerrero N and Mendoza-Cozatl DG (2014) Moving toward a precise nutrition: preferential loading of seeds with essential nutrients over non-essential toxic elements. Front. Plant Sci. 5:51. doi: 10.3389/fpls.2014.00051

This article was submitted to Plant Nutrition, a section of the journal Frontiers in Plant Science.

Copyright (C) 2014 Khan, Castro-Guerrero and Mendoza-Cozatl. This is an openaccess article distributed under the terms of the Creative Commons Attribution License (CC BY). The use, distribution or reproduction in other forums is permitted, provided the original author(s) or licensor are credited and that the original publication in this journal is cited, in accordance with accepted academic practice. No use, distribution or reproduction is permitted which does not comply with these terms. 